
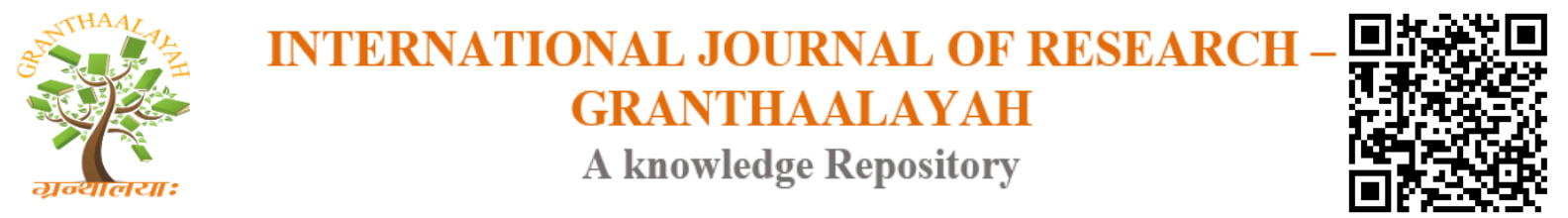

Science

\title{
THE EFFECT OF REAL MODEL IN ENHANCING METACOGNITION OF ABSTRACT PHYSICS TOPIC
}

\author{
I Wayan Distrik ${ }^{1}$, Chandra Ertikanto ${ }^{2}$, Agus Suyatna ${ }^{3}$, Wayan Suana ${ }^{4}$ \\ 1,2,3,4 Physics Education Department, University of Lampung, Indonesia
}

\begin{abstract}
This paper outlines the effect of REAL model in enhancing students' metacognitive abilities on abstract physics topics, such as electricity and magnetism. The study employed a pre-test and posttest quasi-experimental design with a control group. The experiment group $(\mathrm{n}=30)$ was taught using the REAL model while control group $(n=30)$ was taught using the traditional method. REAL model includes recognizing the concept of targets through analogies, explaining concepts with multiple representations, applying concepts to sample solutions, and looking back at selfweakness through reflection self. Pre-test and post-tests were given at the beginning and at the end of the treatment for each group. Data were analyzed by descriptive and inferential methods. The results showed that REAL model has a positive effect in increasing students' metacognitive ability shown by significant $n$-gain difference between experiment and control groups. During the study, students also felt motivated and more confident in solving physics problems shown by more than $80 \%$ of them responded positively to the learning model.
\end{abstract}

Keywords: REAL Mode; Metacognitive Ability; Abstract Physics Material; Electricity and Magnetism.

Cite This Article: I Wayan Distrik, Chandra Ertikanto, Agus Suyatna, and Wayan Suana (2018). "THE EFFECT OF REAL MODEL IN ENHANCING METACOGNITION OF ABSTRACT PHYSICS TOPIC." International Journal of Research - Granthaalayah, 6(6), 389-395. https://doi.org/10.29121/granthaalayah.v6.i6.2018.1383.

\section{Introduction}

Physics is a part of science studied from elementary school to university level. Physics consists of several topics, such as kinematics, dynamics, waves and optics, temperature and heat, electricity and magnetism, etc. Electricity and magnetism topics are one of the most challenging topics. Many problems in electricity and magnetism are very difficult to solve for students $[1,2]$ due to the abstractness and involving complicated mathematics [3]. Therefore it is necessary to have the appropriate thinking and learning strategies. Learning strategies can foster a positive attitude of students in learning [4]. [5] divides the learning model into two major groups, namely the teachercentered and the student-centered interactive learning model. The student-centered learning model 
is an active learning model, which actively involves the students in learning through the process of observing, questioning, experimenting, analyzing, and communicating the results of learning.

The REAL learning model is a student-centered learning model, which is a multiplerepresentation-based learning model consisting of four phases: Recognizing the concept of targets through analogies, explaining concepts with multiple representations, applying concepts to sample solutions, and looking back at self-weakness through reflection self [6]. The REAL learning model is designed in accordance with the mandate of Indonesian Constitution no. 20 of 2003 concerning National Education System, which is further elaborated in Government Regulation no. 19 of 2005 on the National Standard of Education and Regulation of Minister of Education and Culture no. 65 of 2013 on Process Standard in which the learning process is held interactively, inspiring, fun, challenging, and motivate learners to participate actively and provide space for learners to creativity according to their talents and interests. REAL learning model in the first step is recognizing the concept through analogies. Using analogies in initial knowledge is intended to generate new conceptual insights on difficult and abstract materials. Learning by analogy can be convenience to students, learning activity becomes more interesting [7]. Analogy is a process of equalizing between two different concepts which is very appropriate to be applied in abstract materials so that the difficult materials will become easily understood by learners [8, 9]. Learning with analogy strategy can help students to improve understanding and awareness of metacognition [10].

The second step of REAL model is explaining the concept with multiple representations. In this step, students conduct experiments, observations, or reviewing some literature to explain targeted concepts with multiple representations (verbal, virtual, and symbolic). Explaining concepts with multiple representations can overcome cognitive limitations [11], so as to improve the ability to think about cognition (metacognition).

The third step, solving the problem following the example of the solution, means the students do the activities of planning, monitoring, and evaluating what they have been done. The more problems that can be solved correctly, the more students' metacognitive skills increase. The final step of REAL is to look back at the self-strengths and weaknesses through self-reflection. Selfreflection can help students perform analysis and interpretation $[12,13]$, so as to increase students' metacognitive ability. Self-questioning, such as the already known and the unknown concepts is the attempt to improve the metacognitive skills. The REAL model is very practical and effectively applied in student worksheets to enhance conceptual understanding and problem solving [14].

Based on the above explanation, this research focuses on applying REAL model to enhance students' metacognitive ability. Furthermore, this recent research also conducted to explore student's response to REAL model in learning electricity and magnetism topics in the course of Introductory Physics II. To investigate the effectiveness of REAL model on metacognition ability and student's response to REAL model, this study was focused to answer two research questions: 1) what is REAL model effective in enhancing metacognition capabilities demonstrated by the difference in n-gain metacognition capability between the experimental and control classes? 2) What is student's response to the REAL model in learning electricity and magnetism topic. 


\section{Method}

\subsection{Research Design}

This study used a quasi-experimental pre-test-post-test control group design (Figure 1). This research was conducted in the Even Semester Academic Year of 2016-2017 at the University of Lampung, one of the state universities in Indonesia. The number of samples in this study was 60 students enrolling in Introductory Physics II and was divided into 2 classes, class A and class B. Class A was randomly selected as an experiment group taught by REAL model and class B as a control group taught by traditional model.

\begin{tabular}{|ccc|}
\hline 0 & $\mathrm{X}_{1}$ & $0 \& \mathrm{R}$ \\
\hline 0 & $\mathrm{X}_{2}$ & 0 \\
\hline
\end{tabular}
0= Pretes-Postes, $\mathrm{X}_{1}=$ REAL Model
$\mathrm{X}_{2}=$ Traditional Model, $\mathrm{R}=$ = Perception questionnaire

Figure 1: Research Design

\subsection{Data Collection}

The instrument to measure students' metacognitive ability about electricity and magnetism was adapted from a test developed by [15]. The instrument consisting of seven indicators (namely: declarative, procedural, conditional, prediction, planning, monitoring, and evaluation) has three subtopics; electrostatics, electrodynamics, and magnetism. Each subtopic consists of seven questions, with 21 questions in total. The questions are in the form of multiple choice with explanations and essay questions. The test was administered before and after treatments in both the experiment and control groups. On the other hand, the data of students' perception toward REAL learning model was collected through a questionnaire. The questionnaire contains about freedom in interaction, feelings of pleasure, ease in understanding the form of representation.

\subsection{Data Analysis Data}

Data collected in this study were analyzed descriptively and inferentially. Descriptive analysis was performed through transcripts and categorized as low, medium, and high levels. Inferential analysis was implemented using independent sample t-test to test the difference of the score of $n$ gain of metacognitive ability between experiment and control group. The gain score is calculated by reducing the post-test by pre-test scores [16]. The average n-gain can be categorized as: $\langle\mathrm{g}\rangle$ high, if $\langle\mathrm{g}\rangle>0.70 ;\langle\mathrm{g}\rangle$ is, if $0.30<\langle\mathrm{g}\rangle \quad 0.70$; and $\langle\mathrm{g}\rangle \mathrm{low}$, if $\langle\mathrm{g}\rangle 0.30$ [17]. Independent sample t-test was analyzed using SPSS v.22 program. Student's response to REAL learning model was analyzed into positive and negative responses. The positive response indicated when more than $50 \%$ of students liked the model and they did not find difficulties in learning physics materials.

\section{Results}

Before presenting research results of experimental and control groups, groups similarity were checked by conducting independent t-test between experimental and control groups. Independent t-test result was derived $\mathrm{p}>0.05$ as shown in Table 1. It indicated that there were no significant difference between students' initial metacognition ability. 
Table 1: Descriptive statistics and independent t-test on initial group differences

\begin{tabular}{|l|l|l|l|l|l|l|l|}
\hline \multicolumn{1}{|c}{ Pretest type Group } & \multicolumn{1}{c|}{ Descriptive Statistics } & \multicolumn{1}{c|}{ Independent t-test } \\
\hline \multicolumn{1}{|c|}{$\mathbf{n}$} \\
$\begin{array}{l}\text { Metacognition } \\
\text { ability }\end{array}$ & Experimental & 57 & 41.67 & 4.67 & - & 55 & $0.265^{*}$ \\
\cline { 2 - 8 } & Control & 57 & 42.61 & 4.19 & 1.121 & & \\
\hline
\end{tabular}

* Difference is not statistically significant, $\mathrm{p}>0.05$

\section{Metacognitive Ability}

Results of pre-test, post-test, and n-gain of metacognitive ability of experiment and control groups are illustrated in Figure 2.

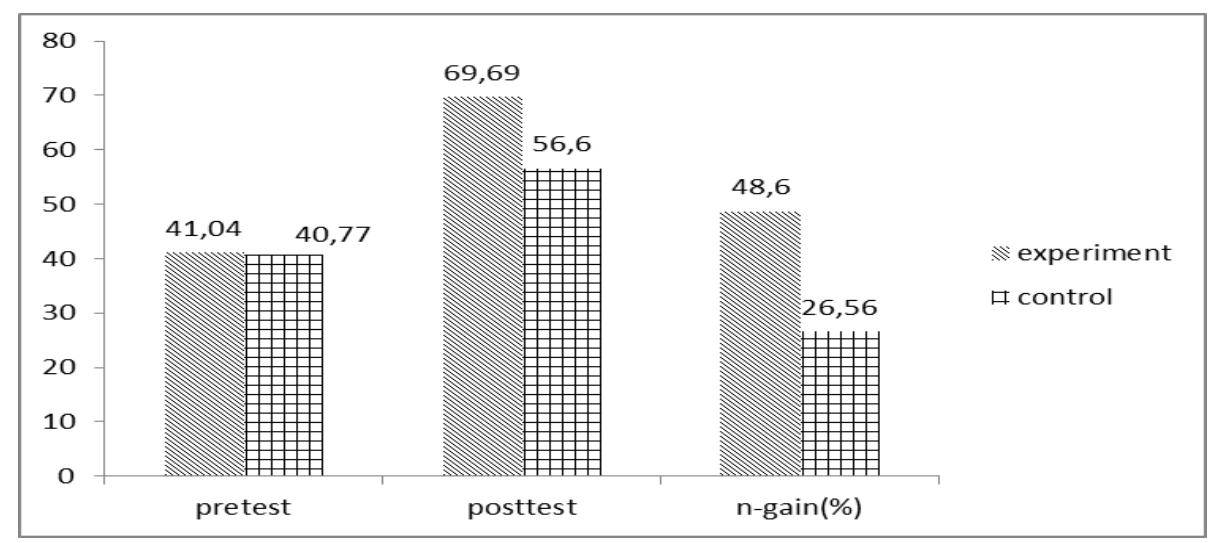

Figure 2: The average of pretest, posttest, and n-gain of metacognition ability

The results of independent sample t-test n-gain score of metacognition ability between experimental and control groups are shown in Table 2.

Table 2: Descriptive statistics and independent sample t-test results of metacognition n-gain

\begin{tabular}{|l|l|l|l|l|l|l|}
\hline \multirow{2}{*}{ Group } & \multicolumn{3}{|c|}{ Descriptive Statistics } & \multicolumn{3}{|c|}{ Independent t-test } \\
\cline { 2 - 7 } & n & N-gain (\%) & S & t & df & P \\
\hline Experimental & 30 & 48.6 & 7.46 & 11.027 & 112 & $0.01 *$ \\
\hline Control & 30 & 26.56 & 5.11 & & & \\
\hline
\end{tabular}

* Difference is statistically significant, $\mathrm{p}<0.05$

Table 2 highlights that the average n-gains of experiment and control groups are 48,6 and 26,56, respectively. Since $\mathrm{p}<0.05$, it indicates that there is a significant difference between the experiment and control groups.

The data of students' perception toward REAL model were collected in the end of the learning process. All students in experiment group gave response to REAL model. The results of students' responses are presented in Table 3.

Table 3: Students' perceptions toward REAL model

\begin{tabular}{|l|l|}
\hline Perception & \% students \\
\hline Positive & 85.72 \\
\hline Negative & 14.28 \\
\hline
\end{tabular}




\section{Discussion}

The results of study (Table 2) showed that the n-gain of metacognitive ability of experiment group was significantly different from the n-gain of control group. It indicates that REAL model is effective in improving students' metacognitive ability. Improvement of the ability of metacognition in electricity and magnetism topic is influenced by the implementation of REAL model. REAL model is able to rise thinking skills of students through learning activities, such as identifying a new concept through analogy, and making connections between target concept and the analogy. Learning by using analogy make students able to elaborate symbols or formulas with a visual analogy. These results reinforce the findings of [18], that the use of analogies helps students in critical thinking and improves the students' long-term memory regarding concepts they had learned. Learning with analogy allows students to remember the concepts that are similar to the concept being studied. Students figure out a similar concept, and recognize the differences and similarities between these two concepts. This means that they plan, evaluate, and monitor the equality of two associated concepts. The step of recognizing concept through analogy is a strategy to improve metacognitive skills, as stated by [13], that the use of prior knowledge that already owned is a strategy of metacognition.

Explaining the concept of using multiple representations can help students obtain additional information in other forms, such as verbal forms, images, and symbolic, so as to improve the process of thinking about thinking. These results reinforce the notion [11] which states that the learning environment with multiple representations can support the process of cognition, limits the interpretation that may occur, and motivate students to build understanding. Representation may also help to integrate new ideas, to construct an understanding of, and displays support concept. This opinion is supported by [19], which is to increase the knowledge of students' metacognition, can be done through declarative knowledge, ie to integrate new ideas with existing knowledge and construct an understanding. Declarative knowledge can be in the form of facts, generalizations, private events, and personal attitudes are organized into theories and personal events [20].

The syntax of applying the concept of following the example of the solution can guide students to apply concepts to problem-solving. Students represent a problem in concrete representation in the form of images, symbols, graphics, as well as in verbal form, display the formulas to be used, and resolve the issue with the correct procedure. Furthermore, interpreting and validating based on the results obtained. Syntax applying the concept following the example of a form scaffolding solutions to students, if the problems facing the problems that are in the zone of potential development, students difficult to solve such problems, it is necessary scaffolding, as an example of a solution. This syntax would allow the student is able to recognize whether the matter can be resolved properly or not, if the student is not sure or not able to resolve the problem, students can use the example of a solution that is in textbooks or worksheets. The REAL learning model through an example solution trains students on the skills plan includes sorting stages performed in solving problems, the application of a certain strategy, so that a complicated problem be easy. Evaluating skills, can be done by assessing the suitability of the procedures used to solving problems, and making conclusions are troubleshooting steps that can improve the ability of metacognition. Syntax 3 can help students improve their knowledge of metacognition (procedural and conditional) and metacognition skills (prediction, planning, monitoring, and evaluation). 
In the last syntax, looking back all the learning activities through self-reflection, lecturer gave questions about what has been done or is being done by the students. Reflection in the research is done by showing one group to present its findings or opinion of the group through presentation, expression and criticizing his opinion. Reflections were assessing something in some way or contemplate yourself about something. The activities carried out in reflection, ie reading the questions well, retrieving information, plan, analyze concepts, make predictions, and monitoring. Reflection associated with metacognition skills, namely planning, predicting, monitoring, and evaluating. These results were confirmed by [21] who said that the activities of reflection includes explaining, analyzing, and evaluating thoughts, assumptions, beliefs basic theory and action, such as prospective reflective, selective reflection and retrospective reflection. Self-reflection plays an important role in developing insights and thinking process. This opinion is supported by [22], which stated that self-reflection is an important strategy to improve the development of insight, enhance cognitive awareness, promote critical thinking, and cause personal transformation. In learning the students feel motivated and easier in understanding abstract concepts that are shown by students' positive responses to the model (Table 3). Over $80 \%$ of students stated that the REAL model with analogy, multiple representation, examples and solutions, and reflection strategies can help them to understand and solve problems in static electricity, dynamic electricity and magnetism.

\section{Conclusion}

Based on independent sample t-test of n-gain of metacognitive ability between experiment and control group, it is obtained that $\mathrm{p}<0.05$, which means that $n$-gain of students taught by REAL model is significantly higher than students taught by traditional model. These results indicate that the REAL model has a significant effect on increasing the metacognitive skills of students in learning electricity and magnetism topics. The application of REAL model enables students to ask questions actively, perform observations and experiment, do analysis, and communicate, in accordance with the learning process set by the Regulation of Minister of Education and Culture No. 65 of 2013. During the learning activity, the abstract concepts become clearer and easier to understand, as indicated by the students' positive perception toward their learning guided by REAL model. However, the REAL model was only applied to a limited topic. Therefore, future research needs to be carried out on the other abstract physics materials.

\section{Acknowledgment}

The authors would like to thank the Institute of Research and Community Service of the University of Lampung which has given financial support to this research.

\section{References}

[1] Demirci, N. (2006). Students Conceptual Knoledge about Electrocity and Magnetsm and its Implications: An Example of Turkish University. Science Education International, 17(1), 49-64.

[2] Luangrath, P., Pettersson, S., \& Benckert, S. (2011). On the use of two versions of the force concept inventory to test conceptual understanding of mechanics in Lao PDR. Eurasia Journal of Mathematics, Science and Technology Education, 7(2), 103-114.

[3] Mur, J., Zaragoza, M. L., Usón, A., Letosa, J., Samplón, M., \& Artal, S. J. (2004). Teaching Electricity and Magnetism in electrical engineering curriculum: applied methods and trends. International Conference on Engineering Education, 50018, 1-11, 
doi=10.1.1.76.7983\&rep=rep1\&type $=$ pdf

[4] Demirci, C. (2017). The Effect of Active Learning Approarch on Attitudes of $7^{\text {th }}$ Grade Students. International Journal of instruction, 10(4), 129 - 144.

[5] Arends, R. I. (2007). Learning to teach. New York: McGraw-Hill

[6] Distrik, I W. (2016). Model Pembelajaran REAL untuk Meningkatkan Kemampuan Metakognisi, Pemahaman Konsep, dan Kemampuan Pemecahan Masalah. Desertasi untuk Gelar Doktor Pendidikan IPA Universitas Negeri Surabaya, Indonesia.

[7] Sarantopoulos, P. \& Tsaparlis, G. (2004). An Analogies in chemistry teaching as a means of attaiment of cognitive and affective abjectives a lognitudinal study in a naturalistic setting using analogies with a strong social content. Chemistry Education research and Practice, 5(1), 33 - 50.

[8] Glynn, S. M. (2008). 5.1 Making science concepts meaningful to students: teaching with analogies. Four Decades of Research in Science Education-from Curriculum Development to Quality Improvement: From Curriculum Development to Quality Improvement, 113.

[9] Oliva, J.M. (2005). What Professional Knowledge Shoal We as Physics Teacher Have about Use of Analogies? Journal Physics Teacher Education. 3(1).

[10] Coll, R. K., France, B., \& Taylor, I. (2005). The role of models/and analogies in science education: implications from research. International Journal of Science Education, 27(2), 183-198, doi.org/10.1080/0950069042000276712

[11] Ainsworth, S. E. (2006). DeFT: A conceptual framework for learning with multiple representations. Learning and Instruction, in press. doi.org/10.1016/j.learninstruc.2006.03.001

[12] Kabilan, M.K. (2007). English Language Teachers Reflecting on Reflections: A Malaysian Experience. TESOL Quarterly, 41(4), 681-705.

[13] Segedy, J.R., Kinnebrew, J.S., Soldberg, B.S., Sottilare, R.A., \& Biswas, G. (2015). Designing Representation and Support for Metacognition in the Generalized Intelligent Framework for Tutoring. Springer International Publishing Switzerland, 663-674.

[14] Suryani, Y., Distrik, I.W., Suyatna, A. (2018). The Practicality and Effectiveness of Students Worksheet Based Multiple Representation to Improve Conceptual Understanding and Students Problem Solving Ability of Physics. International Journal of Research Granthaalayah. 6(4), 166 - 173. https://doi.org/10.5281/zenodo.1243075

[15] Desoete, a, Roeyers, H., \& Buysse, A. (2001). Metacognition and mathematical problem solving in grade 3. Journal of Learning Disabilities, 34(5), 435-449, doi.org/10.1177/002221940103400505

[16] Zwolak, J. P., \& Manogue, C. A. (2015). Assessing student reasoning in upper-division electricity and magnetism at Oregon State University. Physical Review Special Topics - Physics Education Research, 11(2), 1-11, doi.org/10.1103/PhysRevSTPER.11.020125

[17] Hake, R. R. (2002). Relationship of Individual Student Normalized Learning Gains in Mechanics with Gender, High-School Physics, and Pretest Scores on Mathematics and Spatial Visualization. Physics Education Research Conference, 8(August), 1-14.

[18] Spezzini, S. (2010). International Journal for the Scholarship of Teaching and Learning, 4(2).

[19] Woolfolk, A. (2008). Education Psychology. Active Learning Edition, $10^{\text {th }}$ Ed. Penerjemah: Helly Prajitno Soetjipto dan Sri Mulyantini Soetjipto. Penerbit: Pustaka Pelajar. Yogyakarta.

[20] Dahar,R.W. (1996). Teori-teoribelajar.Jakarta:Erlangga, Indonesia.

[21] Fade, S. (2002). Learning and assessing Through Reflection. London Region Dietitians Retrieved from: http://electronicportfolios.org/reflection/RoyalBromptonV3.pdf

[22] Andrusyszyn, M. A., \& Davie, L. (1997). Facilitating Reflection through Interactive Journal Writing in an Online Graduate Course: A Qualitative Study. International Journal of E-Learning \& Distance Education, 12(1), $103-126$.

\footnotetext{
*Corresponding author.

E-mail address: wayandistrik8@gmail.com/chandra_unila@ymail.com/asuyatna@yahoo.com/wsuane@gmail.com
} 